\title{
EFEKTIVITAS MODEL CREATIVE PROBLEM SOLVING BERBASIS APLIKASI BIT.LY DALAM PEMBELAJARAN FISIKA
}

\author{
Asep Ilham Juliansyah ${ }^{1}$, Nana $^{1}$ \\ ${ }^{1}$ Pendidikan Fisika Fakultas Keguruan dan Ilmu Pendidikan Unversitas Siliwangi \\ Jl. Siliwangi No.24 Tasikmalaya, Kota Tasikmalaya, Jawa Barat, Indonesia, (46115) \\ *E-mail : asepilham2407@gmail.com
}

\begin{abstract}
This research uses the bit.ly application as a medium in learning strategies using virtual simulations aimed at increasing students' mastery and understanding in understanding a material. The purpose of this research is motivated by the lack of mastery of the material so that the learning applied is not yet maximal, because it is necessary for innovation in learning by applying the creative problem solving model based on bit.ly application. Creative problem solving model as a problem solving process is accompanied by the use of bit.ly applications so that students are motivated in learning and can improve their learning outcomes and also hone the creativity of a teacher. The method used in this paper is literature study by examining some literature to be analyzed and made conclusions. the results of this study prove that the application of a creative problem solving model based on bit.ly applications as learning innovations can be one of the solutions to problems encountered in the teaching and learning process in the classroom and also facilitate the teacher in delivering a material. The creative problem solving model is applied in high school with several steps: students clarify various problems to solve, then emphasize to better understand students using the bit.ly application. Creative problem solving learning that uses the bit.ly application can activate the creativity of teachers and students so that students become more active in learning. Therefore, the need for a teacher's readiness to always innovate in providing material and also the readiness of a student to accept all forms of innovation.
\end{abstract}

Keywords: Bit.ly Creative Problem Solving, Learning Innovation.

ABSTRAK. Penelitian ini menggunakan aplikasi bit.ly sebagai media dalam strategi pembelajaran menggunakan simulasi virtual bertujuan untuk meningkatkan penguasaan dan pemahaman siswa dalam memahami sebuah materi. Tujuan penelitian ini dilatar belakangi oleh kurangnya penguasaan materi sehingga pembelajaran yang diterapkan belum cukup maksimal, karna itu perlu adanya inovasi dalam pembelajaran yaitu dengan penerapan model creative problem solving yang berbasis aplikasi bit.ly. Model creative problem solving sebagai proses pemecahan masalah yang diiringi dengan penggunaan aplikasi bit.ly agar siswa termotivasi dalam belajar dan dapat meningkatkan hasil belajarnya dan juga mengasah kreativitas dari seorang guru. Metode yang digunakan dalam penulisan ini yaitu studi pustaka dengan mengkaji beberapa litelatur untuk di analisis dan dibuat kesimpulan. hasil penelitian ini membuktikan bahwa penerapan model creative problem solving berbasis aplikasi bit.ly sebagai inovasi pembelajaran dapat menjadi salah satu solusi dari permasalahan yang ditemui dalam proses belajar mengajar di kelas dan juga mempermudah guru dalam penyampaian suatu materi. Model creative problem solving diterapkan di sekolah menengah atas dengan beberapa langkah : siswa melakukan klarifikasi berbagai masalah untuk dipecahkan, kemudian penekanan untuk lebih memahamkan siswa menggunakan aplikasi bit.ly. Pembelajaran creative problem solving yang menggunakan aplikasi bit.ly dapat mengaktifkan kreativitas guru dan murid sehingga murid mejadi lebih aktif dalam pembelajaran. Oleh karna itu, perlunya kesiapan dari seorang guru untuk selalu ber inovasi dalam memberikan materi dan juga kesipan dari seorang murid untuk menerima segala bentuk inovasi.

Kata Kunci: Bit.ly,Creative Problem Solving, Inovasi Pembelajaran,

\section{PENDAHULUAN}


Munculnya berbagai teknologi baru di suatu negara menjadikan persaingan di bidang teknologi semakin ketat. Tren tersebut berkaitan dengan alat yang memiliki kreativitas yang mampu merancang materi dan desain pembelajaran menjadi lebih baik dan lebih tepat. Pada kenyataannya pembelajaran yang ada di sekolah harus menghadirkan berbagai inovasi yang mampu meningkatkan daya kreatif siswa. Siswa tidak hanya mampu untuk mendengar dan memahami suatu pelajaran tetapi bagaimana memiliki keterampilan dalam mengelola informasi yang diberikan pengajar untuk dicerna dengan ideide kreatif. Untuk itu perlunya kesiapan siswa sebagai pelajar dalam memanfaatkan berbagai teknologi secara baik dengan tidak membatasi daya nalarnya terhadap pembaharuan dalam pembelajaran. Sama hal nya dengan siswa, guru pun harus siap dengan segala pembaharuan teknologi di abad 21 ini karena ketika seorang guru bisa memanfaatkan teknologi dengan baik dan menerapkan hal kreativ dalam pembelajaran tidak menutup kemungkinan siswa pun akan menjadi termotivasi untuk lebih kreatif dan juga aktiv pada saat pembelajaran. (Nana, 2018)

Tidak dapat dipungkiri banyak sekali hambatan yang dilalui dalam mengaktifkan daya nalar dan kreativitas siswa dikarenakan tingkat intelengensi yang berbeda-beda. Tentu saja hal tersebut menjadi tolak ukur dalam pembelajaran di kelas maupun di luar kelas. Penyampaian pembelajaran dengan menggunakan teknologi harus memperhatikan berbagai konten yang sesuai dengan batasan umurnya agar tidak terfokus dari inovasi yang digunakan. Namun dalam hal ini, tidak begitu mudah untuk menyebarkan berbagai teknologi yang inovatif di sekolah-sekolah dikarenakan berbagai paham dan sejarah sekolah yang berpengaruh pada pelaksanaanya. Perbedaan tersebut dapat dipengaruhi oleh motivasi yang ingin dicapai oleh guru, karakteristik siswa, cara penyampaian dalam memberi tugas belajar (Findikoglu \& Ilham, dalam Nana, 2018).

Masyarakat di abad 21 membutuhkan kemampuan sebagai kompetensi utama (core competency) karna itu dalam pembelajaran yang sesungguhnya harus memungkinkan terjadinya proses belajar yang (chaeruman uwes anis, 2018) :

- Aktif, memungkinkan siswa dapat terlibat aktif oleh adanya proses belajar yang menarik dan bermakna

- Konstruktif , memungkinkan siswa dapat menggabungkan ide-ide baru kedalam pengetahuan yang telah dimiliki sebelumnya untuk memahami makna atau keingin tahuan dan keraguan yang selama ini ada dalam benaknya

- Kolaboratif, memungkinkan siswa dalam suatu kelompok atau komunitas yang saling bekerjasama, berbagi ide, saran atau pengalaman, menasehati dan memberi masukan untuk sesama anggota kelompoknya.

- Antusias, menjadikan siswa dapat secara aktif dan antusias dalam proses belajar mengajar sehingga bisa mencapai tujuan yang diinginkan.

- Dialog, memungkinkan proses belajar secara inherent merupakan suatu proses sosial dan dialog dimana siswa memperoleh keuntungan dari proses komunikasi tersebut baik di dalam maupun diluar sekolah.

- reflektif, memungkinkan siswa dapat menyadari apa yang telah ia pelajari serta merenungkan apa yang telah dipelajarinya sebagai bagian dari proses belajar itu sendiri (norton, dalam chaeruman 2018)

- High order thinking skills training, memungkinkan untuk melatih kemampuan berpikir tingkat tinggi (seperti problem solving, pengambila keputusan, dll) serta secara tidak langsung juga meningkatkatkan "ICT dan literacy” (fryer, dalam chaeruman 2018)

Selain itu, pentingnya berinovasi dalam pembelajaran agar nantinya mampu bersaing di kancah internasional dengan memperhatikan berbagai kekuatan baik teknologi dari dalam maupun dari luar. Dalam situasi ini, tidak mudah untuk menganggap semuanya mudah karena butuh orang yang benarbenar kreatif (Seryukov, dalam Nana, 2018). 
Di sisi lain, pengalaman yang diperoleh siswa selama pembelajaran di tingkat sebelumnya yang secara sadar maupun tidak sadar akan berpengaruh pada keberhasilannya dalam belajar serta meningkatkan motivasi. Cara untuk meningkatkan motivasi siswa dalam belajar yaitu dengan memberikan berbagai masalah-masalah yang berbeda-beda. Masalah-masalah harus memenuhi kriteria yaitu mampu menciptakan kreatif siswa, dibuat untuk dipecahkan secara berkelompok, berkaitan dengan kekuatan diri sehingga siswa tidak hanya mampu mencerna permasalahan tetapi cara bersosialisasi dengan terlibat dalam diskusi (Valqui Vidal, dalam Nana, 2018).

Masalah tersebut perlu dipecahkan melalui model-model pembelajaran yang inovatif yaitu dengan creative problem solving. Creative problem solving sebagai strategi yang efektif dalam memecahkan berbagai masalah nyata dan bagaimana cara mengatasinya dengan menggunakan daya kreativitas. Strategi ini berkaitan dnegan bagaimana cara memahami tantangan, menghasilkan ide, merencanakan untuk memecahkan masalah dengan mengeksplorasi berbagai data yang ditemui untuk menghasilkan ide (Tseng dkk, dalam Nana,2018).

Aplikasi teknologi informasi dan komunikasi yang merupakan pengembangan teknologi, diantaranya adalah media komputer. Komputer merupakan alat dan aplikasi teknologi berbasis informasi dan komunikasi yang dimanfaatkan sebagai perangkat utama untuk mengolah data menjadi informasi yang bermanfaat dengan memproses, menyajikan, dan mengelola informasi. Pengolahan data dengan komputer disebut dengan Pengolahan Data Elektronik (Electronic Data Processing - EDP)(Nana dan Surahman, 2019;2020).

Masalah-masalah tersebut perlu diselesaikan dengan pembelajaran yang inovatif yaitu melalui model POE2WE. Model pembelajaran POE2WE dapat menjadikan peserta didik sebagai subjek di dalam pembelajaran. peserta didik secara aktif menemukan suatu konsep melalui pengamatan atau eksperimen secara langsung, bukan dari menghafal buku materi maupun penjelasan dari guru (Nana dan Surahman, 2019;2020)..

Penyesuaian gaya belajar dengan model creative problem solving merupakan hal yang penting dengan menyesuaikan inovasi yang dikembangkan. Keberhasilan dalam pencapaian model creative problem solving dapat diiringi dengan penggunaan Aplikasi Bit.ly. Bit.ly sebagai sarana berkomunikasi secara maya. Artinya siswa dapat belajar dengan menggunakan Aplikasi ini sebagai pemacu daya kreatifnya (Boyd, dalam Nana, 2018). Maka dalam hal ini, perlunya membahas bagaimana cara menerapkan model creative problem solving berbasis aplikasi bit.ly sebagai inovasi pembelajaran di Sekolah Menengah Atas.

\section{METODE PENELITIAN}

Penelitian ini menggunakan metode literasi (studi pustaka). Artinya, penulis mengambil data melalui kegiatan membaca literatur yang relevan dengan kajian yang dilakukan . Data dikumpulkan untuk dianalisis kemudian disajikan dalam hasil dan pembahasan agar dapat dibuat kesimpulan.

\section{HASIL DAN PEMBAHASAN}

\subsection{Creative Problem Solving}

Model pembelajaran sebagai upaya untuk meningkatkan keberhasilan belajar siswa. Penerapan model dapat disesuaikan dengan kemampuan, sarana dan prasarana yang berkaitan dengan proses pemecahan masalah (Valqui Vidal, dalam Nana, 2018 ).

Menurut pepkin (Muslich, dalam Sari, 2017). Bahwa model pembelajaran creative problem solving adalah suatu model pembelajaran yang memusatkan pada pengajaran dan keterampilan pemecahan masalah, yang diikuti dengan penguatan keterampilan. Jadi, melalui model pembelajaran ini siswa diharapkan mampu menimbulkan minat sekaligus kreativitas. Pemecahan masalah yang membutuhkan kreativitas dengan mendefinisikan berbagai pertanyaan untuk 
diselesaikan dan dicari solusinya. Penting sekali dalam memahami struktur masalah dengan berbagai pemikiran kreatif. Proses pemecahan masalah melibatkan pengalaman baru yang secara logis di susun dengan sistematis. Masalah juga perlu dilihat dan diketahui kebenarannya (Ridong $\mathrm{Hu}$ et al, dalam Nana,2018). Langkah-langkah dalam model creative problem solving antara lain sebagai berikut; proses pemecahan masalah dengan kreatif dengan menyeleksi informasi baru, masalah yang telah diindentifikasi kemudian di konsep secara komprehensif, proses masalah yang telah di konsep untuk menemukan solusi dari masalah yang nyata (Basadur el al, dalam Nana, 2018).

\subsection{Bit.ly}

Istilah dari Bit.ly berbeda-beda dalam setiap penggunaannya dikarenakan penerapan dari bit.ly itu sendiri, dalam hal ini bit.ly bisa di artikan sebagai alat untuk seseorang untuk menyampaikan sesuatu, artinya dalam pendidikan aplikasi ini dapat digunakan sebagai alat guru untuk memberikan suatu materi agar mempermudah murid memahami materi sekaligus meningkatkan kreativitas murid dan keaktifan murid dalam pembelajaran.

Aplikasi bit.ly ini bisa digunakan secara efektive jika sesuai dengan materi yang di berikan ataupun bisa di katakan sangat efektive jika d terapkan dalam pembelajaran, karena bisa membuat siswa lebih aktif dalam pembelajaran dan juga siswa akan lebih paham memahami suatu materi yang di anggap sulit, karena dalam penerapannya bit.ly secara virtual dan mudah untuk di gunakannya.

\subsection{Inovasi Pembelajaran}

Mengapa integrasi teknologi informasi dan komunikasi (TIK) dalam pembelajaran penting ? Karena, kita hidup dalam era teknologi komunikasi instan (Dryden dan Voss, dalam Chaeruman,2018). Keberadaan teknologi informasi dan komunikasi telah mengubah cara manusia hidup di era informasi saat ini. Begitu pula halnya dengan kecakapan/kompetensi manusia generasi abad 21. Perserikatan bangsa-bangsa (PBB) bahkan menyatakan bahwa masyarakat abad 21 harus memiliki keterampilan melek teknologi informasi dan komunikasi, keterampilan berkomunikasi efektif dan keterampilan berkolaborasi (UNESCO,dalam Chaeruman,2018). Semua itu adalah merupakan karakteristik masyarakat berpengetahuan (knowledge-based society) dalam era global saat ini.

E-Learning merupakan suatu istilah yang dapat kita temukan dalam dunia komputer atau internet. Kata e-learnig terdiri atas 2 (dua) bagian yaitu "e" yang berarti "elektronik" dan "learning" yang berarti "pembelajaran". Jadi kata e-learning dapat diartikan sebagai suatu sistem pembelajaran yang menggunakan perangkat elektronik sebagai media pembelajarannya. (Rahmasari \& Rismiati,dalam Nana dkk,2019). Selanjutnya dikatakan bahwa sistem elearning diharapkan bukan sekedar menggantikan metode dan materi pengajaran konvensional tetapi dapat juga menambahkan metode maupun strategi baru dalam proses pembelajaran.

Penerapan pembelajaran melalui enternet (e-learning), merupakan suatu media baru yang dapat mengatasi sikap pasif peserta didik. Menurut (Sadiman, Rahardjo, Haryono, \& Harjito,dalam Nana dkk,2019) dengan penggunaan media belajar yang tepat, sangat berguna untuk :

a. Menambah kegairahan dalam belajar,

b. Memungkinkan interaksi secara langsung,

c. Memungkinkan peserta didik belajar secara mandiri. Belajar mandiri adalah suatu cara belajar yang dilakukan oleh peserta didik secara bebas menentukan tujuan belajarnya, merencanakan proses belajarnya, strategi belajarnya, menggunakan sumber-sumber belajar yang dipilihnya, 
membuat keputusan akademik, dan melakukan kegiatan-kegiatan untuk tercapainya tujuan belajar. Karena itu belajar mandiri membutuhkan motivasi, keuletan, keseriusan, kedisiplinan, tanggung jawab, kemauan dan keinginan tahuan untuk berkembang dan maju dalam pengetahuan. (Yamin, dalam Nana dkk,2019)

Dalam Kamus Besar Bahasa Indonesia arti dari inovasi adalah sebagai pemasukan atau pengenalan hal-hal yang baru, penemuan baru yang berbeda dari yang sudah ada atau yang sudah dikenal sebelumnya baik berupa gagasan, metode atau alat (KBBI, dalam Fahmi, 2017). Dengan kata lain inovasi adalah suatu hal yang baru, yang keberadaannya sangat memberikan manfaat. Inovasi erat kaitannya dengan pembelajaran yang melibatkan guru dan peserta didik. Sedangkan pembelajaran menurut (Gagne dan Briggs, dalam Fahmi, 2017) adalah suatu system yang bertujuan untuk membantu proses belajar siswa, yang berisi serangkaian peristiwa yang dirancang, disusun sedemikian rupa untuk mempengaruhi dan mendukung terjadinya proses belajar siswa yang bersifat internal. Artinya ada proses atau kegiatan yang sangat membantu interaksi guru dan peserta didik dalam memperoleh pengetahuan. Dari pengertian inovasi dan pembelajaran tersebut maka makna inovasi pembelajaran merupakan metode baru yang berbeda yang digunakan untuk membantu proses interaksi guru dan peserta didik dalam memeperoleh pengetahuan.

\subsection{Penerapan Model Creative Problem Solving Berbasis Aplikasi Bit.ly Sebagai Inovasi Pembelajaran di Sekolah Menengah Atas}

Salah satu masalah dalam proses pengajaran di sekolah yaitu bagaimana mengembangkan keterampilan siswa agar menjadi kreatif dan sesuai dengan bakatnya. Setiap siswa dilatih sesuai dengan keterampilan dan bakat yang dimiliki agar dapat meningkatkan motivasi. Keterampilan yang harus dimiliki oleh siswa berkaitan dengan penalaran verbal-numerik, pemikiran secara abstrak, mengingat informasi sesuai dengan keabsahan data (Cetinkaya, dalam Nana, 2018). Untuk itu mengembangkan keterampilan siswa dapat melalui berbagai inovasi dalam pembelajaran yaitu dengan menggunakan model yang tepat dan sesuai dengan karakteristik siswa. Salah satu model yang dapat di terapkan dalam pembelajaran agar melatih siswa menjadi creative yaitu dengan model pembelajaran creative problem solving.

Creative problem solving merupakan salah satu pemecahan masalah secara kreatif yang dianggap berpengaruh pada kreativitas siswa di masa depan. Beberapa peneliti menyakini bahwa kreativitas berupa masalah yang akan dipecahkan, sejumlah ide yang relevan, proses memberikan solusi dari divergen ke kovergen (Lin,dalam Nana, 2018). Sebagaimana penjelasan sebelumnya bahwa masalah dapat dipecahkan dengan mengindentifikasi dan menyeleksi masalah sesuai dengan kreatif (Wimmer,dalam Nana, 2018). Proses mengindentifikasi dengan model pemecahan masalah secara kreatif maka diperlukan pembaharuan yang berbasis teknologi yaitu dengan penggunaan Aplikasi Bit.ly. Aplikasi bit.ly ini yang mudah digunakan untuk memberikan suatu materi terhadap murid secara virtual yang dapat mengembangkan wawasan siswa dalam belajar agar termotivasi (Pifarre el al,dalam Nana,2018).

\section{PENUTUP}

Dari berbagai pembahasan yang telah dijabarkan dapat ditarik kesimpulan dan dimaknai bahwa model pembelajaran yang berbasis masalah secara kreatif dapat meningkatkan motivasi siswa agar lebih terpacu dalam keberhasilan belajarnya. Kesesuaian keterampilan dan bakat siswa dapat berpengaruh pada hasil yang dicapai sehingga perlunya keprofesionalan guru sebagai pengajar agar dapat menjadikan siswa menjadi lebih kreatif dengan media internet yaitu penggunaan blog.

\section{UCAPAN TERIMA KASIH}


Terima kasih kepada semua pihak yang telah membantu kelancaran pembuatan artikel ini khusus nya Dosen mata pelajaran Fisika sekola II. Dr. Nana, M.Pd. Sehingga artikel yang dibuat bisa menjadi lebih baik lagi.

\section{DAFTAR PUSTAKA}

Nana. (2018). Penerapan Model Creative Problem Solving Berbasis Blog sebagai Inovasi Pembelajaran di Sekolah Menengah Atas dalam Pembelajaran Fisika. Prosiding SNFA (Seminar Nasional Fisika dan Aplikasinya). 190-195

Nana, Surahman E. (2019). Pengembangan Inovasi Pembelajaran Digital Menggunakan Model Blended POE2WE di Era Revolusi Industri 4.0. Prosiding SNFA (Seminar Nasional dan Aplikasinya), 8290.

Nana dan Surahman E. (2020). POE2WE Model as an Alternative for Learning Physics in Industrial Revolution 4.0 Era. Advances in Social Science, Education and Humanities Research, 397(2), 1013-1022

Fahmi, (2017). Inovasi Dalam Pembelajaran Adalah Sebuah Keharusan [Online]. Tersedia : https://sekolahprogresif.sch.id/inovasi-dalam-pembelajaran-adalah-sebuah-keharusan/

Chaeruman, dkk (2018), “ Inovasi Pembelajaran Yang Mengintegrasikan TIK” SlideShare [Online]. Tersedia : https://www.slideshare.net/uweschaeruman/inovasi-pembelajaran-yangmengintegrasikan-tik

Norton, Priscilla ; dan spargue, Debra ; (2001), “ Technology for Teaching”. Allyn and Bacon, Boston, USA.

Ftyer, Wesley A.; (2001), "Strategy for effective Elementary Tecnology Integration", [Online]. Tersedia : http://www.wtvi.com/teks/integrate/tcea2001/powerpointoutline.pdf 